017 Global Fashion Management Conference at Vienna Proceedings: 216-224 (July 2017) https://doi.org/10.15444/GFMC2017.03.06.01

\title{
BE SOCIAL AND BE TUNED: EVALUATE YOUR BRANDS IN ONLINE COMMUNITIES
}

\author{
Silvia Ranfagni, University of Florence, Italy ${ }^{1)}$ \\ Monica Faraoni, University of Florence, Italy
}

\begin{abstract}
The paper proposes an analytical approach that explores brands in virtual environments by combining indicators of consumer brand alignment with measurements of social engagement. The results illustrated can be useful to devise adjustments to brand communication. The analysis is applied to brands belonging to the fashion industry.
\end{abstract}

Keywords: brand identity, brand image, social engagement, online communities

\section{INTRODUCTION}

The life of a brand is both physical and virtual; it more and more is being played out in online markets, where it seeks to unfold all its relational potential (Aaker, 1999). Brands are experienced in virtual consumer communities which are interactive places populated by consumers who share information, perceptions and, thus, also sensations (Szmigin, Canning \& Reppel, 2005). The information they provide can drive companies in reconstructing consumer behaviors and in understanding how consumers relate with brands (Muniz \& O'Guinn, 2011). A topic that recent studies (Mollen \& Wilson, 2010; Brodie, Ilic, Juric \& Hollebeek, 2013) investigate is the engagement that a brand produces among consumers. It is seen as the level of a customer's cognitive, emotional and behavioral investment in specific brand interactions (Hollebeck, 2011, p. 6). If investigated in online contexts, this engagement can take on, according to Mollen and Wilson (2010), the form of cognitive and affective commitment to an active relationship with the brand as personified by the website or other computer-mediated entities designed to communicate brand value (p. 5). The cognitive engagement identifies the consumer's degree of positive brand-related affects in a particular consumer/brand interaction, while the emotional engagement translates into a consumer's level of brand-related thought processing and elaboration in a particular consumer/brand interaction (Hollebeek, Glynn \& Brodie, 2014, p. 154). Both are distinct from behavioral engagement, which most attracts the attention of businesses; this is in fact given by the time and energy the consumer spends in interacting with the brand. All these are closely interrelated. Today there is a diffusion of monitoring platforms that measure a kind of general engagement a brand generates on the web and thus, how much online consumers speak about it. But alone these data do not provide enough details to make brand decisions (Murdough, 2009). They should be compared with other information that makes it possible to

\footnotetext{
1) monica.faraoni@unifi.it
} 
interpret them in an objective way. This information may concern data on the alignment between the brand as it is perceived by consumers and the brand as it is defined by the company. They emerge from interdisciplinary research methods applied to online communities (Crawford Camiciottoli, Ranfagni \& Guercini, 2014); their production allows to fill research gaps emerging in the studies on brand image. These studies in fact, explore the impact of marketing choices on brand perception without comparing the ensuing consumers' brand associations with those that company defines and communicates (Häubl \& Elrod, 1999; Schoormans \& Robben, 1997; Czellar, 2003). Moreover, the brand perception is investigated not through online research techniques but through the conventional ones belonging to qualitative or quantitative methods (Till, Baack \& Waterman, 2011). Regardless of the method, measurements that synthetize brand image versus brand identity matching are important as the level of brand equity and thus, the differential response to the marketing of a brand depends on their values (Keller, 1993; Erdem, 2016; Venkat, and Kerimcan, 2016). In this paper we illustrate how to build specific indicators of brand alignment by exploring online communities and how to use them in a combined way with data on the related brand social engagement (resulting from Talkwalker and Social Mention) in order to provide information that can serve to adequate orient branding policies. We focus the analysis on the traits of brand personality and thus on the "set of human characteristics associated with a brand" (Aaker, 1997, p. 347) that makes the brand a "brand persona" (Herskovitz \& Crystal, 2010). Moreover the context of the analysis is the world of fashion. Here, the online communities are digital platforms where consumers interact intensively and animate discussions exchanging ideas and information (Boyd, Okleshen \& Tolson, 2007; Rickman \& Cosenza, 2007).

\section{METHODOLOGICAL APPROACH}

The analytical approach we used to determine the indicators of brand alignment to be combined with data on the engagement that a brand produces online was inspired to an interdisciplinary approach that has recently emerged in marketing literature (Crawford Camiciottoli, Ranfagni \& Guercini, 2014; Ranfagni, Crawford Camiciottoli \& Faraoni, 2016). It follows netnographic rules to identify and collect digital texts (Kozinets, 2002) and uses the quantitative techniques of text mining to extract linguistic data (Witten, 2005). As indicated by it, we followed the following steps.

(i) The selection of a sample of brands for study. We focused on those found in the fashion blog Style.com and in the social media monitoring tools Talkwalker and Social Mention. We made an explorative analysis on ten brands ${ }^{1}$.

(ii) The collection of data involved two sources, one external and one internal. The external source consists of texts written by consumers and posted on the Syle.com blog. These texts were chosen as they had an excellent performance record in terms of data traffic, membership and links; moreover, the posts and comments were archived for extended periods of time (from August 2008 through August 2015). The internal source, on the other hand, consisted of texts contained in the digital spaces created and

${ }^{1}$ For reasons of confidentiality, we have decided to preserve the anonymity of the fashion brands involved in the research. 
maintained by the company, such as the company's website and Facebook page, which provide descriptions of the brand personality.

(iii) The text files contained in the company and consumer datasets were then subjected to the analytical text-mining procedures (Swales \& Burke, 2003). As Ranfagni, Crawford and Faraoni (2016) show, we used these procedures to isolate and extract the adjectives derivable from the basic features of brand personality proposed by Aaker (1997). Technically, the adjectives were subjected to a process of grammatical tagging (using the software CLAWS4) that labels each word according to grammatical function (for example VV for verb, JJ for adjective and AT for article). Then, through another software (WordSmith Tools, Scott 2010) we extracted from the files all the words tagged JJ together with the sentences in which they occur. We decided to discard from the analysis the adjectives not related to the brand as well as those that were neutral or not significant (those relating to color, size, dimension and nationality). The list of adjective types for each brand was set against the personality adjectives occurring in the respective blog files. This comparison was facilitated and made systematic with the help of another software program, AntConc (Anthony, 2011), which allows the researcher to carry out automatic searches for more than one adjective within a predefined language corpus. Table 1 shows the brands investigated, the number of adjective types communicated by the company (section A), the number of words per blog file, the number of shared adjective types that also consumers use and the number of times consumers associates each adjective type to the brand (section B).

(iv) On the basis of these data we produced the resulting indicators of consumer brand personality alignment (CBPA). These are the consumer brand personality matching (CBPM) (Ranfagni, Crawford Camiciottoli \& Faraoni, 2016) and the brand personality coverage $\mathrm{BPC}_{(\mathrm{CP} / \mathrm{CN})}$ (Ranfagni, Faraoni \& Crawford Camiciottoli, 2016). The CBPM relates for each brand the number of shared adjectives to the number words composing the blog files and then normalizing the resulting value by 1000 . The higher the values of the CBPM, the greater the number of adjectives in common that occur at least once per 1000 words of text produced by consumers. It is a vertical measurement of the brand matching. The $\mathrm{BPC}_{(\mathrm{CP} / \mathrm{CN})}$ evaluates how much the adjective types adopted by consumers overlap with the adjective types used by the company in its brand communication. It emerges by comparing the $\mathrm{BPC}_{(\mathrm{CP})}$, which measures the numerousness of the adjective types per 1000 words of the blog files, in the event all the adjective types used by the company were also used by the consumers in their brand narrations, and the $\mathrm{BPC}_{(\mathrm{CN})}$, which calculates the numerousness of shared adjective types per 1000 words of the blog file. The resulting differential value once is related to $\mathrm{BPC}_{(\mathrm{CP})}$ determines the value of $\mathrm{BPC}_{(\mathrm{CP} / \mathrm{CN})}$. The more this value is low, the more the adjective types recognized by the consumer cover the variety of the adjectives used by the company in brand communication. It is a horizontal measurement of the brand matching. The combination of the CBPM and of the BPC $(\mathrm{CP} / \mathrm{CN})$ produces four situations where different levels of vertical alignment (how much is the alignment) are combined with different level of horizontal alignment (on what the alignment is).

(v) Subsequently, the values of the $\mathrm{CBPM}$ and $\mathrm{BCP}_{(\mathrm{CP} / \mathrm{CN})}$ were enriched by the measurements of social engagement (SE) extracted from the platforms Talkwalker and 
Social Mention. Each of them measures the social engagement in different ways. Talkwalker includes "blogs; news sites; forums; number of Facebook likes + number of comments on the article + number of shares on Facebook of the URL + number of tweets on Twitter of the URL; Facebook: sum of shares, likes and comments; Twitter: number of retweets; Istagram: sum of likes and comments" (www.talkwalker.com). Social Mention measures "the likelihood that a brand is being discussed in social media and comes from a very simple calculation: phrase mentions within the last 24 hours divided by total possible mentions" (www.socialmention.com). The data relative to the two measurements of social engagement were gathered in August 2015. Combining the results obtained by crossing $\mathrm{CBPM}$ and $\mathrm{CBN}_{(\mathrm{CP} / \mathrm{CN})}$ with the level of social engagement is possible to identify consequences in terms of brand communication.

\section{APPLICATIONS AND MAIN RESULTS}

- Comparing consumer brand alignment indicators. From our analysis (table 1), it emerges that the values of the CBPM oscillate from a minimum of 0,95 for Alfa to a maximum of 5,165 for Eta. In general, considering all the CBPM values of the brands investigated, they may be reasonable grouped in low (0.90-1.09), medium-low (1.101.97), medium-high (1.98-3.17) and high (3.18-5.16). As regards the value of $\mathrm{BPC}_{(\mathrm{CP} / \mathrm{CN})}$, the results show that for the brand Iota the adjective types recognized by consumers cover the highest level of adjective types used by the company in its communication, while the correspondence is lower for the brand Beta. In addition to Iota, the cases in which the coverage gap of the adjective types is lower are those of Kappa (62.5\%) and of Epsilon $(63.15 \%)$. Considering that companies tend to speak about brand more on the web than on traditional media (Harris \& Rae, 2010), the percentage levels of the lack of coverage $\mathrm{CBPC}_{(\mathrm{CP} / \mathrm{CN})}$ among the brands examined may be reasonable aggregated in the following way: high if above $81,42 \%$ (coverage attained below 18.58\%); medium-high is in the range between $75.19 \%$ and $81.41 \%$ (coverage attained between $18.59 \%$ and $24.81 \%$ ); medium-low if between $65.78 \%$ and $75.18 \%$ (coverage between $24.82 \%$ and $34.22 \%$ ); low if below $65.77 \%$ (coverage above $34.23 \%$ ). A first comparison may be made between the two kinds of CBPM indicators; this leads to the following diverse situations.

(i) Cognitive brand matching. High CBPM values are accompanied by low values of $\mathrm{BPC}_{(\mathrm{CP} / \mathrm{CN})}$ and thus of lacking coverage. The variety of brand language and the intensity with which company and consumers use it are similar. This is the situation in which the match between brand personality communicated and that perceived is at its highest (Delta, Epsilon, Kappa).

(ii) Cognitive brand mismatching. This includes those cases in which low CBPM values combine with high levels of lacking coverage. The number of brand personality adjectives that both company and consumers employ is low; then, these adjectives reflect a small part of the range of adjectives the company uses when it talks about brand (Alfa, Theta, Gamma).

(iii) Vertical brand matching. In this case both $\mathrm{CBPM}$ and $\mathrm{BPC}_{(\mathrm{CP} / \mathrm{CN})}$ values are high. When consumers speak about the brand, they adopt with high frequency the personality adjectives that company communicates; but these common adjectives cover a low rate of the common adjective types. Consumers do not use the variety of personality adjectives the company uses (Beta, Zeta, Eta). 
(iv) Horizontal brand matching. This involves low CBPM values combined with low $\mathrm{BPC}_{(\mathrm{CP} / \mathrm{CN})}$ values. Consumers speak about the brand making use with a low frequency of common personality adjectives, which cover, however, a considerable share of the adjective types employed by the company (Iota). ${ }^{2}$

The comparisons between the $\mathrm{CBPM}$ and $\mathrm{BPC}_{(\mathrm{CP} / \mathrm{CN})}$ indicators can be combined with the different levels of social engagement.

-Adding the measurements of social engagement. On the basis of the data collected we have identified the following levels of social engagement: (a) high: the measurement of engagement of Talkwalker is greater than the value of 100,000 and/or that of Social Mention is above the level of 50\% (Beta, Gamma, Theta,); (b) medium: the level of engagement provided by Talkwalker is between 10,000 and 100,000 and/or of Social Mention is between 30\% and 50\% (Alfa, Delta, Eta, Iota); and (c) low: the measurements resulting from Talkwalker and Social Mention are lower than those characterizing the medium level (Epsilon, Zeta, Kappa). Now we are going to show how the analysis of the consumer brand matching indicators together with the measurements of social engagement can help managers determine their branding policies. It is on this that attention is now focalize.

\section{DISCUSSION}

If we set the results of social engagement against the levels of cognitive brand matching/mismatching the situations that emerge are diverse as well as the different decisions it may result in terms of brand communication. One situation combines on the one hand, cognitive brand matching with high SE (a) or low SE (b); and on the other, cognitive brand mismatching with high SE (c) or low SE (d). In (a) the company will seek to preserve the current brand communications: there is high brand rumor, which is followed by a perception of personality in line with the identity that is transferred to market. In (b) the company could develop mediated communication (e.g. bloggers) capable of animating the social connectivity of the brand. In (c) and (d), the company should adopt "revitalizing strategy" (Keller, 2003, p.634) by refreshing the existing brand traits or by identifying new ones. Thus, the brand communication could be reviewed on the basis of choices aimed at reviewing the brand concept. While in (c) these choices are necessary to clean the SE of the existing disalignment it embeds, in (d) they create the SE from scratch on the basis of a revised brand. Other situations are the followings: horizontal brand matching with high SE (e) or low SE (f); and vertical brand matching with high SE (g) or low SE (i). In all these cases, the company should review brand communication on the basis of a "reinforcement strategy" to strengthen the existing brand traits. In (e) and in (f), the aim is to intensify also by using social media communication the connective strength of the brand personality in the mind of consumers so that their accounts concerning the brand are intensely evocative of personality traits. While in (e) the interventions could reinforce the SE among consumers, in (f) they could contribute to the development of the SE. In (g) and (i) the reinforcement of brand identity is due to the

2 An example of calculation applied to the brand Alfa (for data used, see table 1). CBPM = $3 / 3157 * 1000=0,95 ; \mathrm{BPC}(\mathrm{CP})=18 / 3157 * 100=5,70 ; \mathrm{BPC}(\mathrm{CN})=3 / 3157 * 1000=0,950 ; \mathrm{BPC}(\mathrm{CP})-\mathrm{BPC}(\mathrm{CN})$ $=4,75 ; \mathrm{BPC}(\mathrm{CP} / \mathrm{CN})=4,75 / 5,70 * 100=83,3 \%$. 
need the company has to amplify the range of the perceived personality traits. It can do this by creating brand communications connections between the adjectives that consumers recognize and those that they do not recognize. While in (g) this amplification needs to take place without altering a SE which conceals a brand perception based on a specific nucleus of personality associations, in (i) the increase should result from the attempt to make the new personality traits as motors of SE. Situations of medium social engagement level have not been commented. We think in fact that in these cases companies will tend to carry out the same actions as in cases of low social engagement. These actions will vary, of course, according to the type of alignment that accompanies the SE.

\section{CONCLUSION}

The use of social media as tools to communicate and to determine branding policies is by now more and more widespread among companies. The analysis we have proposed is focalized on online communities, it could be a valid support for monitoring the effects that strategic brand decisions produce. It is still explorative and inevitably must, to some extent, be refined; it is not, in other words, without its limits. One of these is that the value of engagement on social media is based on the analysis of data stemming from only two platforms, that is, Talkwalker and Social Mention. Moreover the extraction of data on the perception of brand personality is based solely on the blog style.com. In this case as well it would be advisable to widen the field of investigation to include other blogs and forums monitored by social platforms available on the web. Finally, as possible future research developments it would be interesting to verify the existence of relations between social engagement, cognitive brand matching/mismatching and brand performances.

\section{REFERENCES}

Aaker, J. L. (1999). The malleable self: The role of self-expression in persuasion. Journal of Marketing Research, 36(1), 45-57. doi: 10.2307/3151914.

Aaker, J.L. (1997). Dimensions of brand personality. Journal of Marketing Research, 34(3), 347-356. doi: 10.2307/3151897.

Anthony, L. (2011). AntConc (Version 3.2.4) [Computer Software].

Tokyo,Japan:Waseda University. Retrieved from http://www.antlab.sci.waseda.ac.jp/.

Boyd Thomas, J., Okleshen Peters, C., \& Tolson, H. (2007). An exploratory investigation of the virtual community MySpace. com: What are consumers saying about fashion?. Journal of Fashion Marketing and Management: An International Journal, 11(4), 587-603. doi: 10.1108/13612020710824625.

Brodie, R. J., Ilic, A., Juric, B., \& Hollebeek, L. (2013). Consumer engagement in a virtual brand community: An exploratory analysis. Journal of Business Research, 66(1), 105-114. doi:10.1016/j.jbusres.2011.07.029.

Crawford Camiciottoli, B., Ranfagni, S., \& Guercini, S. (2014). Exploring brand associations: an innovative methodological approach. European Journal of Marketing, 48(5/6), 1092-1112. doi: 10.1108/EJM-12-2011-0770. 
Czellar, S. (2003). Consumer attitude toward brand extensions: an integrative model and research propositions. International Journal of Research in Marketing, 20(1), 97 115. doi: 10.1016/S0167-8116(02)00124-6.

Erdem, T., Keller, K. L., Kuksov, D., \& Pieters, R. (2016). Understanding branding in a digitally empowered world. International Journal of Research in Marketing, 33(1), 3-10.

Harris, L. \& Rae, A. (2010). The online connection: transforming marketing strategy for small businesses. Journal of Business Strategy, 31(2), 4 - 12. doi $10.1108 / 02756661011025017$.

Häubl, G., \& Elrod, T. (1999). The impact of congruity between brand name and country of production on consumers' product quality judgments. International Journal of Research in Marketing, 16(3), 199-215. doi: 10.1016/S0167-8116(99)00011-7.

Herskovitz, S., \& Crystal, M. (10). The essential brand persona: storytelling and branding. Journal of Business Strategy, 31(3), 21-28. doi: 10.1108/02756661011036673.

Hollebeek, L. (2011). Exploring customer brand engagement: definition and themes. Journal of strategic Marketing, 19(7), 555-573. doi: 10.1080/0965254X.2011.599493.

Hollebeek, L. D., Glynn, M. S., \& Brodie, R. J. (2014). Consumer brand engagement in social media: Conceptualization, scale development and validation. Journal of Interactive Marketing, 28(2), 149-165. doi: 10.1016/j.intmar.2013.12.002.

Kozinets, R. V. (2002). The field behind the screen: Using netnography for marketing research in online communities. Journal of Marketing Research, 39(1), 61-72. doi: 10.1509/jmkr.39.1.61.18935.

Mollen, A., \& Wilson, H. (2010). Engagement, telepresence and interactivity in online consumer experience: Reconciling scholastic and managerial perspectives. Journal of Business Research, 63(9), 919-925. doi: 10.1016/j.jbusres.2009.05.014

Muniz, A. M., \& O'Guinn, T. C. (2001). Brand community. Journal of Consumer Research, 27(4), 412-432. doi: 10.1086/319618

Murdough, C. (2009). Social media measurement: It's not impossible. Journal of Interactive Advertising, 10(1), 94-99. doi: 10.1080/15252019.2009.10722165

Ramaswamy, V., \& Ozcan, K. (2016). Brand value co-creation in a digitalized world: An integrative framework and research implications. International Journal of Research in Marketing, 33(1), 93-106.

Ranfagni S., Faraoni, M. \& Crawford Camiciottoli, B. (2016). The brand personality in online communities. Micro \& Macro Marketing, 1: 55-76. doi: 10.1431/82868

Ranfagni, S., Crawford Camiciottoli, B. C., \& Faraoni, M. (2016). How to measure alignment in perceptions of brand Personality within online Communities: interdisciplinary insights. Journal of Interactive Marketing, 35(3), 70-85. doi: 10.1016/j.intmar.2015.12.004.

Rickman, A.T., \& Cosenza, R. M. (2007). The changing digital dynamics of multichannel marketing: The feasibility of the weblog: text mining approach for fast fashion trending. Journal of Fashion Marketing and Management: An International Journal, 11(4), 604-621. doi: 10.1108/13612020710824634

Schoormans, J. P., \& Robben, H. S. (1997). The effect of new package design on product attention, categorization and evaluation. Journal of Economic Psychology, 18(2), 271-287. doi: 10.1016/S0167-4870(97)00008-1. 
Scott, M. (2010). Wordsmith Tools Version 5.0, Oxford University Press, Oxford.

Swales, J. M., \& Burke, A. (2003). "It's really fascinating work": Differences in evaluative adjectives across academic registers. Language and Computers, 46(1), 1-18. Doi: $10.1163 / 9789004334410$

Szmigin, I., Canning, L., \& Reppel, A. E. (2005). Online community: enhancing the relationship marketing concept through customer bonding. International Journal of Service Industry Management, 16(5), 480-496. doi: 10.1108/09564230510625778.

Till, B. D., Baack, D., \& Waterman, B. (2011). Strategic brand association maps: developing brand insight. Journal of Product \& Brand Management, 20(2), 92-100. Doi: $10.1108 / 10610421111121080$

Witten, I. H. (2005). Text mining. In Singh, M. P. (Ed.). Practical handbook of internet computing (pp. 14-1). Boca Raton, Fl. Chapman \& Hall/CRC Press. 
2017 Global Fashion Management Conference at Vienna Proceedings

Table 1. An overview of elaborated digital data (personality adjectives from company and blog files) and of values of CBPA indicators and of SE measurements

\begin{tabular}{|c|c|c|c|c|c|c|c|c|c|c|c|}
\hline \multirow{2}{*}{ Brand } & \multirow{2}{*}{\begin{tabular}{|c|}
$\begin{array}{c}\text { Section A } \\
\text { Company } \\
\text { File }\end{array}$ \\
$\begin{array}{c}\text { Adjective } \\
\text { types } \\
\text { communicat } \\
\text { ed }\end{array}$ \\
\end{tabular}} & \multicolumn{3}{|c|}{$\begin{array}{c}\text { Section B } \\
\text { Blog File }\end{array}$} & \multicolumn{4}{|c|}{$\begin{array}{c}\text { Section C } \\
\text { CBPA Indicators }\end{array}$} & \multicolumn{3}{|c|}{$\begin{array}{c}\text { Section D } \\
\text { Social Engagement } \\
\text { Measurements } \\
\end{array}$} \\
\hline & & $\begin{array}{c}\text { Shared } \\
\text { adjective } \\
\text { types }\end{array}$ & $\begin{array}{l}\text { Number } \\
\text { of shared } \\
\text { adjectives }\end{array}$ & Words & CBPM & $\mathrm{BPC}_{(\mathrm{CN})}$ & $\mathrm{BPC}_{(\mathrm{CP})}$ & $\begin{array}{r}\mathrm{BPC} \\
\mathrm{CP} / \mathrm{CN}) \\
\end{array}$ & $\begin{array}{c}\text { Talk } \\
\text { Walker }\end{array}$ & $\begin{array}{c}\text { Social } \\
\text { Mention }\end{array}$ & SE \\
\hline Alfa & 18 & 3 & 3 & 3157 & 0.950 & 0.950 & 5.702 & 83.333 & 5 & 42 & \begin{tabular}{|l} 
MEDIU \\
$\mathrm{M}$
\end{tabular} \\
\hline Beta & 96 & 4 & 7 & 2028 & 3.452 & 1.972 & 47.337 & 95.833 & 11500 & 66 & HIGH \\
\hline $\begin{array}{l}\text { Gamm } \\
\text { a }\end{array}$ & 41 & 6 & 8 & 8855 & 0.903 & 0.678 & 4.630 & 85.366 & $3 \mathrm{M}$ & 55 & HIGH \\
\hline Delta & 38 & 13 & 17 & 3507 & 4.847 & 3.707 & 10.835 & 65.789 & 4500 & 41 & \begin{tabular}{|l} 
MEDIU \\
$\mathrm{M}$
\end{tabular} \\
\hline $\begin{array}{l}\text { Epsilo } \\
\mathrm{n}\end{array}$ & 19 & 7 & 11 & 2800 & 3.929 & 2.500 & 6.786 & 63.158 & 936 & 2 & LOW \\
\hline Zeta & 36 & 5 & 7 & 2145 & 3.263 & 2.331 & 16.783 & 86.111 & 432 & 14 & LOW \\
\hline Eta & 70 & 13 & 24 & 4647 & 5.165 & 2.798 & 15.063 & 81.429 & 11200 & 42 & \begin{tabular}{|l} 
MEDIU \\
$\mathrm{M}$
\end{tabular} \\
\hline Theta & 12 & 3 & 3 & 2738 & 1.096 & 1.096 & 4.383 & 75.000 & 133400 & 53 & HIGH \\
\hline Iota & 19 & 9 & 18 & 11344 & 1.587 & 0.793 & 1.675 & 52.632 & 62100 & 48 & $\begin{array}{l}\text { MEDIU } \\
\mathrm{M}\end{array}$ \\
\hline Карра & 16 & 6 & 13 & 2860 & 4.545 & 2.098 & 5.594 & 62.500 & 2700 & 5 & LOW \\
\hline
\end{tabular}

